\title{
Fine Structure of Podocytes in the Bovine Renal Corpuscle
}

Hiroto MIYATA, Mitsuo ABE*, Kazushige TAKEHANA, Kenji IWASA, Takeo HIRAGA, Osamu YAMADA, Takahiro HIRATSUKA, Jerry MASTY ${ }^{1)}$, and Mamoru YAMAGUCHI ${ }^{1)}$

Department of Veterinary Anatomy, School of Veterinary Medicine, Rakuno Gakuen University, Ebetsu, Hokkaido 069, Japan and ${ }^{1)}$ Department of Veterinary Anatomy and Cellular Biology, The Ohio State University, Columbus, Ohio 43210, U.S.A.

(Received 6 April 1994/Accepted 9 December 1994)

ABSTRACT. Thick primary processes issued from the hemispherical or plate-like cell bodies of podocytes in bovine renal corpuscles. These processes branched into secondary and tertiary ones, but no fine pedicels were observed on the outer surface of the podocytes by scanning electron microscopy, because each primary process closely interdigitated with those of adjacent cells. Many pedicels, however, were observed under the processes by using the freeze-fractograph and a transmission electron microscope.-KEY wORDs: bovine, podocyte, renal corpuscle.

Morphological reports on several species indicate that glomerular podocytes consist of many primary processes which extend radially from the cell body containing the nucleus. The thicker of these processes further branch to form secondary and, at times, tertiary processes. The pedicels (a term used here for the terminal processes) protrude like ferns $[2-4,6,7,11]$. Recently, the morphological change in renal tissues associated with human renal disorders has been analyzed at the electron microscopic level. Podocytes involved in the filtration mechanism of the glomerulus have been reported to change in renal disorders $[1,5,9,10]$. In veterinary medicine, renal disorders are common in many species, but electron microscopic studies of podocytes are limited to certain experimental animals, including mice, rats, and rabbits [2, $4,6,11]$. In this scanning electron microscopic study, we focused on the podocytes of normal renal corpuscles of healthy cows to obtain morphological characteristics as a basis for future studies of renal disorders in veterinary medicine. We found that bovine podocytes have a distinct morphology which differs from that of the species previously studied.

Kidneys were obtained from eighteen healthy Holstein cows, aged 1 to 10 years, after exsanguination at the slaughterhouse or Large Animal Clinical Center of Rakuno Gakuen University. As the control samples, three mice (BALB/c) and three pigs (crossbreed of Landrace, Large White and Hampshire stock), were slaughtered under the same conditions to distinguish species-specific features from effects of exsanguination.

For scanning electron microscopic observation of the glomerular surface, pieces $(1 \mathrm{~mm} \times 1 \mathrm{~mm} \times 1 \mathrm{~mm})$ of kidney were immersed in a fixative containing $3 \%$ glutaraldehyde in $0.1 \mathrm{M}$ phosphate buffer at $\mathrm{pH} 7.2$ for 2 hr. Specimens were rinsed in the same buffer and then dehydrated in a graded series of ethanol and immersed in isoamyl acetate. Some of the specimens were frozen and cracked. After being subjected to critical point drying, these specimens were coated with gold in an ion coater and examined with an HHS-2R microscope (Hitachi). For

\footnotetext{
CoRrespondence to: ABE, M., Department of Veterinary Anatomy, School of Veterinary Medicine, Rakuno Gakuen University, 582 Bunkyodai-Midorimachi, Ebetsu, Hokkaido 069, Japan.
}

transmission electron microscopic observation, specimens were fixed with $3 \%$ glutaraldehyde in $0.1 \mathrm{M}$ phosphate buffer for $2 \mathrm{hr}$, post-fixed with $1 \%$ osmium tetroxide in 0.1 $\mathrm{M}$ phosphate buffer for $1 \mathrm{hr}$, and embedded in Quetol 812 by the conventional methods. The sections were stained with uranyl acetate and lead citrate, and examined with a JEM-100S microscope (JEOL). An indication of kidney function was evaluated by nature of bladder urine by use of the N-MULTISTIX-III (AMES) test.

Many processes extended from the hemispherical or plate-like cell body. The mean size of bovine podocytes was $8.4 \mu \mathrm{m}(\mathrm{n}=1,500$, range: $7.0-12.0 \mu \mathrm{m})$. The mean width of the primary processes was $2.1 \mu \mathrm{m}(\mathrm{n}=1,500$, range: $1.4-2.5 \mu \mathrm{m})$. These processes of the bovine podocytes densely covered the surface of glomerular capillaries and were interdigitated. Thus, most of the pedicels could not be seen touching the basement membrane (Fig. 1). The mean size of slits between adjacent processes was $200 \mathrm{~nm}(\mathrm{n}=1,500$, range: $180-210 \mathrm{~nm})$. However, on rare occasions pedicels issuing toward the basement membrane from the processes were observed (Fig. 2). In the freeze-fractograph, dense pedicels were revealed aligned in parallel below the processes (Fig. 3). Through transmission electron microscopy, numerous thin pedicels were observed on the basement membrane under the processes with intermediate filaments and microfilaments (Fig. 4). Urine analysis indexes for each cow were within clinically normal values.

The podocytes of mice and pigs covered the surface of capillaries by extending the pedicels like ferns as in previous reports $[2-4,6,7,11]$. The slit between the adjacent processes of the bovine podocytes averaged 200 $\mathrm{nm}$, considerably smaller than slits of the mouse and pig, with the mean size of $1.0 \mu \mathrm{m}(\mathrm{n}=1,500$, range: $0.8-1.2$ $\mu \mathrm{m})$. However, the mean width of the bovine primary processes was $2.1 \mu \mathrm{m}$, considerably larger than the mean width of $1.0 \mu \mathrm{m}$ in both the mouse and the pig $(\mathrm{n}=1,500$, range: $0.8-1.3 \mu \mathrm{m})$. Thickening of the processes of the podocytes during ischemia or dehydration of the kidney was also reported in the rabbit [8].

We confirmed that the ultrastructural features of the podocytes of pig and mice killed by phlebotomy were consistent with those in other reports $[2,4,6,11]$ and were different from those of cows (Data are not shown). Thus, 

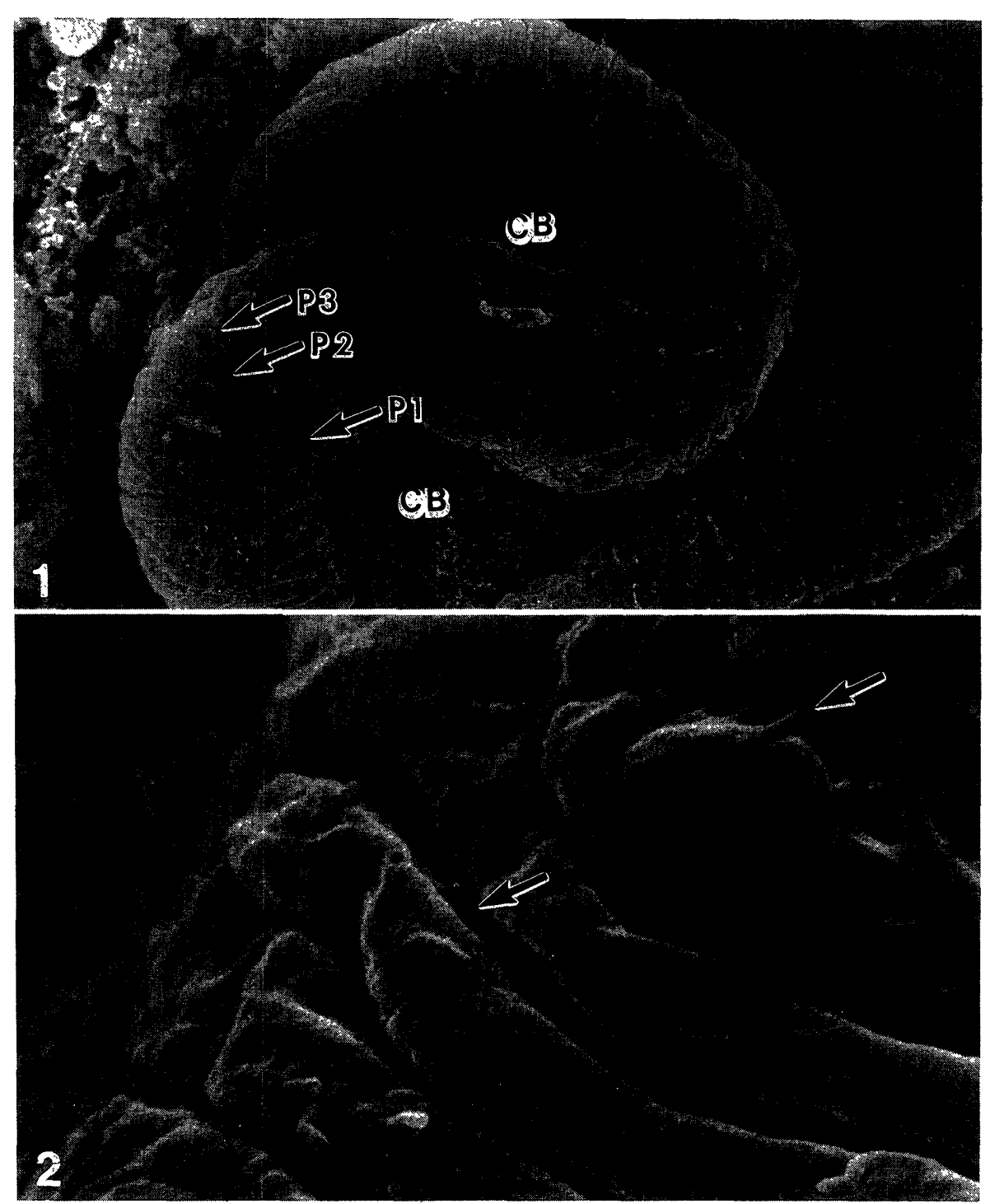

Fig. 1. The podocytes of a four-year-old cow. Primary (P1), secondary (P2) and tertiary processes (P3) extend from the cell body (CB). Since these processes cover the surface of glomerulus capillaries by coming close together and interdigitating with each other, most of the pedicels cannot be observed. $\times 1,600$.

Fig. 2. The podocytes of a seven-year-old cow. Some pedicels (arrows) are seen extending from the narrow slits between the processes. $\times 17,000$.

the unique structure of the bovine glomerular podocytes observed in the present study might be species-specific.

\section{REFERENCES}

1. Arakawa, M. and Tokunaga, J. 1986. Jpn. J. Nephrol. 22: 243-248 (in Japanese).

2. Bloom, W. and Fawcett, D. W. 1986. pp. 728-755. In: A Textbook of Histology, 11th ed., W. B. Saunders, Philadelphia.

3. Buss, H. and Kronert, W. 1969. Virchows. Arch. Abt. B. Zellpathol. 4: 79-92.

4. Fujita, T., Tokunaga, J., and Miyoshi, M. 1970. Arch. Histol. Jpn. 32: 99-113.
5. Kouda, Y., Ishiyama, T., Suzuki, Y., Fukagawa, M., Shimotori, T., and Arakawa, M. 1985. Jpn. J. Nephrol. 27: 21-31 (in Japanese with English summary).

6. Miyoshi, M., Fujita, T., and Tokunaga, J. 1970. Arch. Histol. Jpn. 33: 161-178.

7. Moffat, D. B. 1975. pp. 71-100. In: The Mammalian Kidney, Cambridge Univ. Press, London.

8. Racusen, L. C., Prozialeck, D. H., and Solez, K. 1984. Am. J. Pathol. 114: 157-163.

9. Yamanaka, N. 1983. Kidney and Dialysis 15: 27-34 (in Japanese).

10. Yanagisawa, T., Sugimoto, J., Midoro, K., and Fujiwara, K. 1986. Jpn. J. Vet. Sci. 48: 1173-1182.

11. Yoshinari, T. and Fujita, T. 1982. Arch. Histol. Jpn. 45: 99-109. 

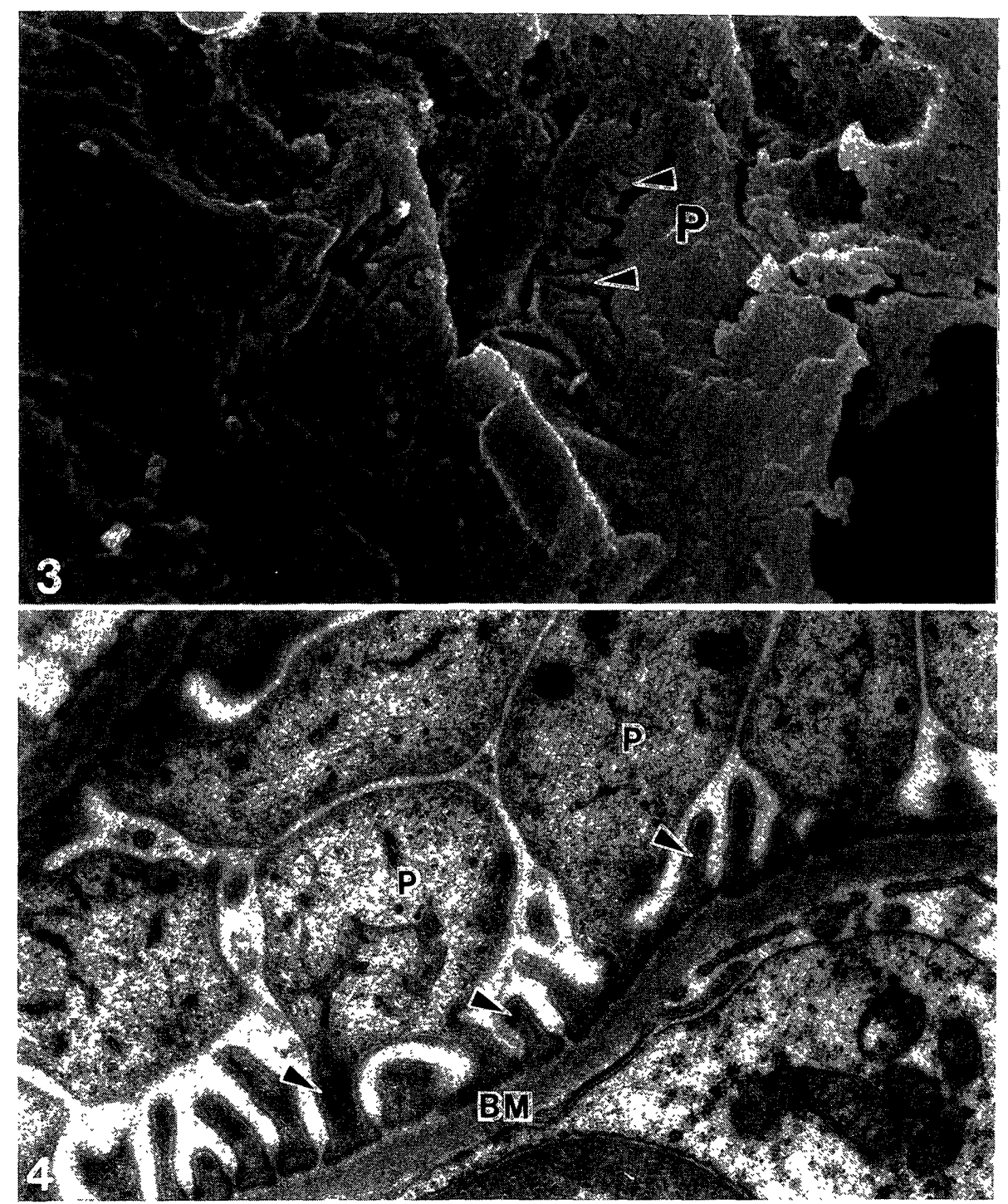

Fig. 3. Fractured surface of the glomerular capillary of a seven-year-old cow. The pedicels (arrow heads) are observed densely aligned in parallel below the processes $(\mathrm{P}) . \times 9,900$. Fig. 4. Transmission electron micrograph of the podocytes of a five-year-old cow. The processes (P) are close to adjacent processes. Many pedicels (arrow heads) are on the outer surface of the basement membrane $(\mathrm{BM}) . \times 17,000$. 